\title{
Ethnography on the Cyberian Frontier ${ }^{*}$
}

\author{
Rhian Morgan \\ James Cook University, Townsville
}

I stepped out of the teleport station and looked over to the glittering high-rises that stretched towards the purple skyline, framing the entrance to the port. I ran silently over the fauxwooded boardwalk towards the buildings, skipped effortlessly up multiple flights of stairs and looked back over the sea, away from the city and across to the mountainous wilderness of Calypso. This was Port Atlantis, this was Entropia, and I had arrived. My mission was to produce an ethnographic account of life within this virtual world; as the "dialogue box" in the corner of the computer screen filled with nonsensical chatter, emoticons, and abbreviations, I realised that this task would not be as straightforward as I had anticipated.

(Entropia - field diary, 17/8/2011)

\begin{abstract}
Virtual worlds are persistent, multi-user, computer generated environments, established and maintained via internet technologies. Cyber-ethnography is the adaptation of the ethnographic method to the study of virtual worlds. The collective and interactive nature of life in contemporary digital space has incited the interest of a new generation of ethnographers and awakened the discipline of anthropology to the possibility of studying a form of sociality that exists beyond the confines of the physical realm. Virtual world communities are crafted through an amalgamation of technology and human sociality; by studying these emergent worlds, ethnographers are able to observe culture in the making. After twenty years of development, virtual worlds have emerged as distinct domains of human being worthy of study in their own right. However, as a discipline cyber-ethnography is still trying to establish itself and demonstrate the contributions it can make to both anthropology and the arts and social sciences in general. The developments within cyberethnography have mirrored advancements in computing technologies and reflect wider debates within the discipline of anthropology. The following review shows how online ethnography can help us understand our digital life-worlds. The article begins by defining virtual worlds, describing the virtual field site Entropia Universe and documenting the development of the discipline. It culminates with an exploration of being and place in cyberspace, drawing on ethnographic data from the virtual world Entropia Universe.
\end{abstract}

\footnotetext{
* This paper was first conceived and presented at the TransOceanik Links colloquium at The Cairns Institute. The original publication details are: Morgan, R. (2011). Ethnography on the cyberian frontier. LiNQ: Generations 38, 117-130.Permission to reprint was granted by the editorof LiNQ, Dr Victoria Kuttainen.
} 


\section{Defining virtual worlds}

$\mathrm{V}$ irtual worlds have proven to be some of the most interesting domains for ethnographic research on the internet. Virtual worlds can be distinguished from other online domains through their use of avatars, virtual landscapes, and synchronous communication. These worlds can be either text-based or graphical, but all use avatars (digital representations of self) as the main means of interaction. Virtual worlds, the other important component of cyber-ethnography, consist of digital landscapes, created either through textual description or graphical depiction, which provide users with "a sense of geography and terrain” (Bell, 3). This sense of geography has resulted in a linguistic distinction between virtual worlds and other online spaces; users talk about being "in" virtual worlds, whereas people talk about being “on” blogs, forums, or social networking sites. A further difference between virtual worlds and other online realms is synchronous interaction. Within virtual worlds users interact in real time. Other forms of online interaction, such as emails, status updates and comments, or forum posts, are asynchronous; users cannot guarantee, or expect, that other users will be online at the same time and respond directly. Another defining feature of virtual worlds is their persistence.

Virtual worlds continue to exist even when you are not there; community life persists and is not dependent on the presence of any individual user (Bell, 3). The persistent nature of virtual worlds prompts people to form long and short term social groups (Bell, 3). The virtual world continues to turn, even when you are not there; this knowledge, combined with a sense of obligation towards one's virtual social network, results in people investing a large amount of time and energy in online worlds. Participants spend an average of twenty hours per week within virtual worlds (Yee qtd. in Moore, Gathman, and Ducheneaut, 230). Mediated agency, virtual landscapes, persistence, and real time interaction have transformed virtual worlds into social landscapes and they are therefore best analysed using the ethnographic method, as opposed to the literary analysis that one would apply to, say, life writing.

\section{Entropia Universe}

I stood on the dock at Port Atlantis for a while listening to the chat. Multiple threads of conversation overlap, mixed with notifications of various wins occurring across Calypso. "Lyne JD Rover killed a creature (Araneatrox Mature) with a value of 601PED. A record has been added to the Hall of Fame.", "lol Tel was in the wall”, "bugs lol” ,":)” "Sam Sammy Samson manufactured an item (Simple 1 plastic springs) with a value of 61PED” " $u$ found what i hide ;)".

People run purposely back and forth from the teleporter to trade and repair terminals in the city, stocking up with weapons and ammunition from the auction, ready to head out for the next hunt. Others hang around chatting and joking. One girl dances on the wall, I giggle and wave, she "lols" (laughs out loud), and waves back, "gl”(good luck) she calls, "u2” (you too) I reply "thx"(thanks). Someone shouts out, asking for a taxi to an area I don't recognise, "you'll need a small car" someone replies, the dialogue box erupts in "lol"s and "rofl"s (rolling on the floor laughing), I don't get it. I head back towards the teleporter by the water and log off. 


\section{(Entropia field diary 17.8.2011)}

Entropia Universe (EU) is a Massively Multiplayer Online Role Playing Game

(MMORPG/MMO) based in multiple virtual worlds. The game was launched in 2003 and now has an estimated population of approximately one million registered users worldwide. The game world consists of a three dimensional computer generated environment, where players from around the globe interact via humanoid avatars. The virtual universe is comprised of multiple planets, run as franchises by different software companies. The original and most densely populated planet is Calypso and this is where the bulk of my field research, on the nature of being in virtual space, is taking place. The primary method of investigation is online ethnographic participant observation, complemented by semistructured interviews with other players. The field work began in August, 2011, and will continue for approximately twelve months.

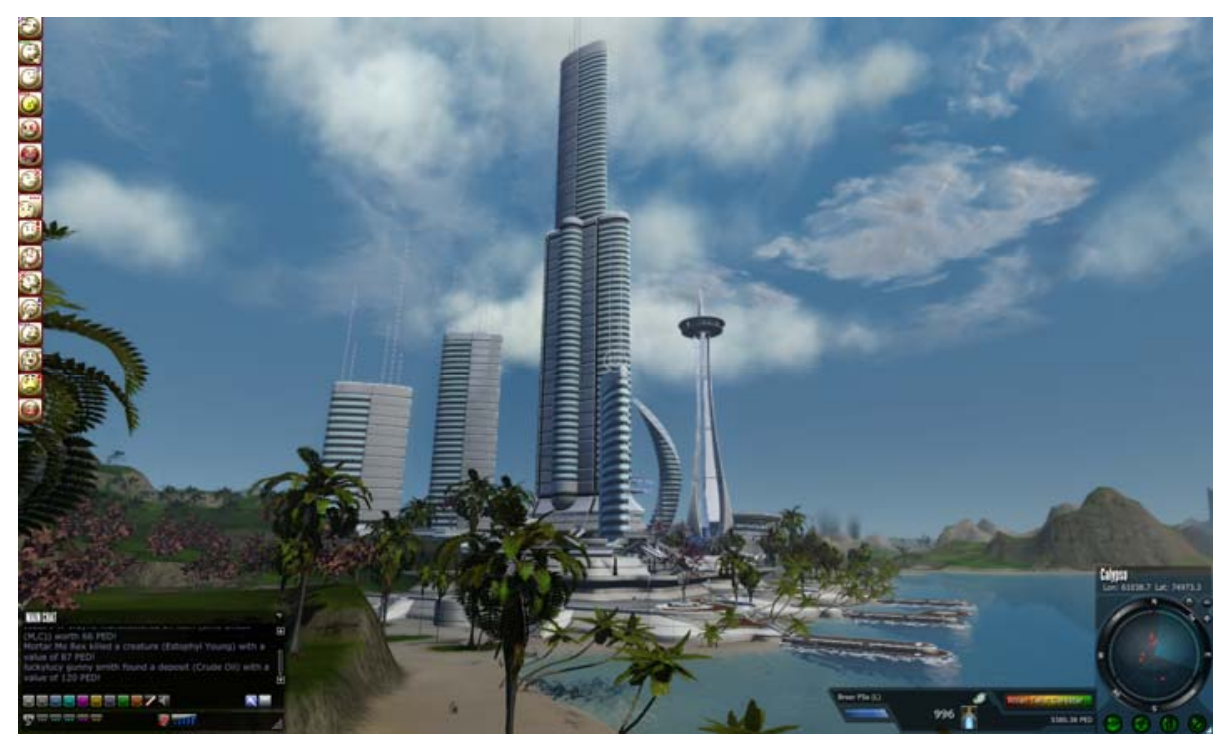

Entropia Universe: Port Atlantis (screen shot 11.11.2011)

Online games are, like film and literature, narrative mediums. Ethnographic analysis draws heavily on the rhetorical analysis that originates in literary studies and is, therefore, well suited to the study of these worlds. For instance, Entropia's game narrative relates themes of interstellar colonisation to visions of a post-apocalyptic future, enacted in a present virtual space. Yet, the fantasy of the game-world is curtailed by the incorporation of a "real-cash economy" into game-play. The real-cash economy means that players can deposit real money into the game, at a fixed exchange rate of US\$1 to 10PED (Project Entropia Dollars), in order to purchase virtual goods. The incorporation of a cash economy means that, unlike most fantasy narratives, this virtual world is also a commercial space of online exchange, where fiction and reality collide. Winnings generated through game-play can be legally transferred in real-life currency and paid out onto players' real-world bank accounts, or re-used within the game to purchase virtual goods and real-estate. However, it's not just about investment, profit, and loss. Upon further investigation it becomes apparent that players purchase goods, like cars, clothing and accessories, that do not provide them with any monetary returns. This is more than just a game: it is a self-contained world, a socio-cultural and economic context, within which spending $\$ 30$ on pair of virtual jeans seemed to make perfect sense. The cyberethnographic method provides a means of exploring experiences of being and place within this virtual world.

\section{Cyber-ethnography: developing a discipline}


"The romance of the Net came not from how it was built or how it worked but from how it was used" (Hafner and Lyon, 218).

The development of sizeable and diverse online communities began as soon as ARPANET ${ }^{\dagger}$ gave way to the public internet in the early 1990s. The technological limitations of early internet and computing hardware meant that these communities were predominantly textbased; interactions took the form of typed communications via email lists, bulletin boards and chat services, or in text-based virtual worlds, such as multiuser domains (MUDs) and multiuser object orientated worlds (MOOs) ${ }^{\ddagger}$ (Wood and Smith, 10). It was the text-based nature of these early virtual communities and the peculiarities of the social worlds that were forming within them that first prompted the interest of ethnographers.

The first ethnographic account of life in a virtual world was Rosenberg's 1992 documentation of life in WolfMOO, a text-based virtual world (Bartle, 491; Boellstorff, 53). Rosenberg conducted "several weeks" (Bartle, 491) of ethnographic field work within WolfMOO, in order to provide a documentation of the emergent game culture on this platform. One of the most striking features of Rosenberg's ethnographic article is his inclusion of exerts of MOO text:

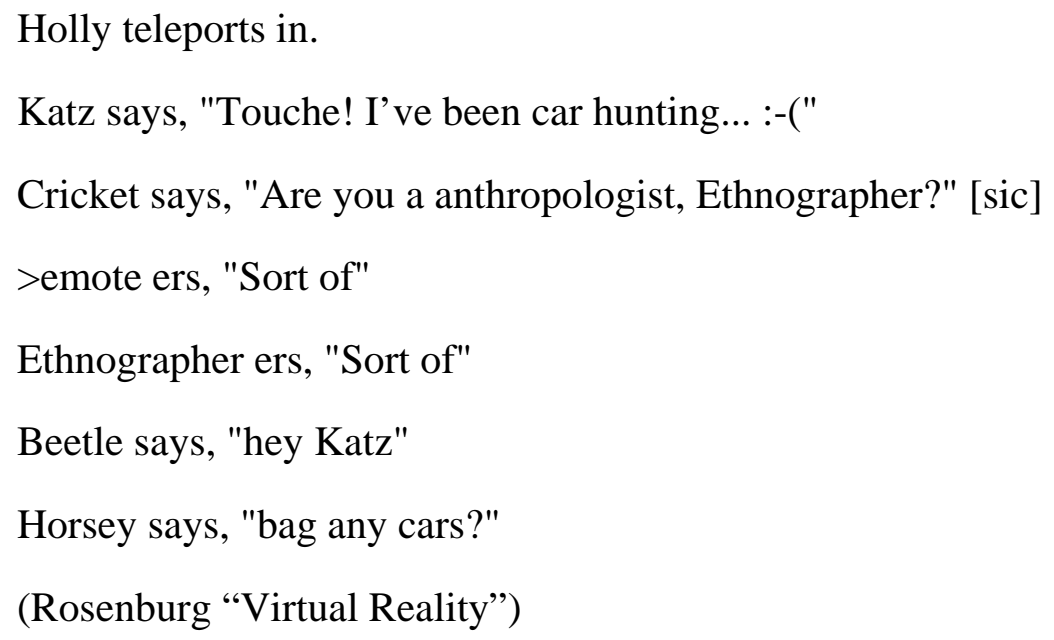

At first glance these excerpts appear to be nonsensical ramblings (not unlike the text chat in Entropia's dialogue box). Yet, they actually demonstrate how virtual communities form linguistic conventions and the parallel threads of conversation that occur within virtual worlds. Emoticons ${ }^{\S}$ are used to indicate emotional states and overcome the ambivalence of brief textual communications, which do not allow for adequate inflection, and within textbased worlds "emote" functions are used as substitutes for body language and narration (Cherny "Modal complexity"). Early socio-linguistic studies of MUDs and MOOs demonstrated that it was possible to conduct ethnographic field work purely online and that, just like in the real world, online ethnographers needed to familiarise themselves with the

\footnotetext{
† ARPANET was a joint project of the U.S dept. of defence’s Advanced Research Projects Agency Network and MIT, launched in 1969, and the precursor to the contemporary internet

${ }^{\ddagger}$ MUDs (Multi-User Dungeons/Domains) are text-based online multiplayer virtual worlds, where players act and interact via typed commands. These virtual worlds consist of textual descriptions of players and places rather than graphical 3d environments. MOOs (Multi-user Object Orientated worlds) are object based online textual virtual worlds where players are able to initiate programming changes on the game server which affect how the server (and thus the virtual world) behaves for all players.

$\S$ Emoticons are adaptations of punctuation symbols used to express affect within digital communications e.g. colons parenthesis are used to construct smiley faces and sad faces.
} 
"languages" of the communities they were studying. Some of these early cyber-ethnographers also began to explore the notion of cyberspace as place.

The notion of cyberspace as place began as an analytic metaphor, used to explain the manner in which users mapped their way through the labyrinths of so-called "rooms" on MUD/MOO servers (Masterson, 2). However, this analytic metaphor failed to capture the affective character of these virtual places. Language and literary narratives have long been recognised for their ability to construct and evoke a "sense of place" (Tuan, 685). Within text-based virtual worlds, the creative and metaphorical power of language was simply being applied to a new medium. This creation of place through narrative is particularly apparent within Dibbell's ethnographic account of life in the text-based virtual world LambdaMoo. Dibbell's ethnography combines transcripts of the online text describing the Lambda cyberscape with a phenomenological account of life in Lambda, which demonstrates the dynamic creation of place, through narrative, within a virtual world (39 - 42). The foundations for contemporary ethnographic studies of cyberspace as place were laid during these early years of the internet. However, this vein of study took a slight hiatus during the turn of the century as sociolinguistic studies of text-based virtual worlds gave to way to the examination of the humancomputer interface.

The ethnographic focus on users of internet technologies gained prominence during the mid to late 1990s and early 21st century. This movement reflected the normalisation of computing technologies and an analytic interest in the manner in which these technologies were shaping societies and peoples' conceptions of self (Turkle, 10; Wellman, 125). Internet researchers, such as Turkle, Hakken, and Miller and Slater, began to look into the real-life impacts of computing technologies and cultural responses to these technologies. These researchers conceptualised the internet as a cultural artifact and examined the relationships people formed with, and through, the use of this artifact. Consequently, they tended to focus on real-life engagement with users, rather than purely online participant observation. The shift towards real-life contact with users, and away from the online-only engagement characteristic of early cyber-ethnographic studies, prompted debates about the necessity of the face-to-face encounter within digital ethnography.

The face-to-face encounter with members of the culture one is study has been considered an essential component of ethnographic research since the time of Malinowski. Real-time participation and observation are now often deemed fundamental to the creation of a legitimate account of a particular cultural group (Hakken, 46). Early cyber-ethnographers were often able to forgo the face-to-face encounter with participants due to their focus on language use within online communications. However, the user-centered focus, common during the second stage of cyber-ethnographic research, caused digital ethnographers to reiterate the significance of the face-to-face encounter. The legitimising role allocated to reallife engagement caused a crisis of validity for cyber-ethnographers, such as Hine (49), who chose to engage with participants purely via the internet. Researchers using online only methods found that they had to argue for the legitimacy of their accounts of online cultures in the face of criticisms that research conducted only online ignores the social and political contexts within which engagements with internet technologies occur (Teli, Pisanu and Hakken, 2).

Christine Hine solved the problem of the face-to-face encounter by studying a topic on the internet (the Louise Woodward trial, which took place in the U.S. in 1997), rather than a 
virtual location (67). This topical approach to the internet is well suited to the study of online communities that converge around specific subjects, such as fan- or news-based webpages, forums, and email lists, but it does little to aid the ethnographer who wishes to focus on a specific virtual world community. Hine offers some assistance to online ethnographers studying discrete virtual world by arguing that when interactions between community members take place online only, the practice of 'online only' ethnography is justified because of the symmetrical relationships this methodology creates between researchers and research participants (49). Hine argues that ethnographers should attempt to create symmetrical power relations with users by avoiding offline contact when this is not a norm of the community one is studying. This is one of the first articulations of an argument for the study of online cultures in context that would come to characterise the third stage of cyber-ethnographic research.

The third distinct stage of cyber-ethnographic research began at the turn of the millennium. This third stage coincided with the development of graphical virtual worlds and the growth of social networking sites and was characterised by a divergence within the discipline. The growth of social-networking sites meant that the user-centered approach to the internet continued, as sites such as MySpace and Facebook lend themselves to an online/offline examination of the performance of identity on the internet (see Rybas \& Gajjala, "Developing Cyberethnographic Research Methods"; Driscoll and Gregg, "My Profile"; Evans

"Webnography"). The simultaneous expansion of graphical virtual worlds led to a resurgence in online-only ethnography and studies of cyberspace as place.

Graphical virtual worlds tend to support much larger user bases than text-based virtual worlds, with player numbers running into the millions rather than thousands (Kelly, 2). The users' experience of space within these worlds is primarily visual, rather than textual. These worlds are usually either centered on game play (as in the MMORPGs World of Warcraft, Everquest, and Entropia Universe) or social interactions (as in Second Life). The use of humanoid avatars within graphical virtual worlds adds a new dimension of complexity to users' experiences of self and place on the internet. Within these graphical worlds you craft your representation of self visually, and your actions take on an embodied fluidity not possible within text-based worlds. The visual and embodied nature of interactions with these online worlds reawakened ethnographers to the possibility of studying cyberspaces as places.

The resurgence of online-only ethnography, which accompanied the expansion of graphical virtual worlds, required cyber-ethnographers to, once again, engage with assumptions about the primacy of the face-to-face encounter within ethnographic research. In Coming of Age in Second Life, the first full ethnographic monograph on life in a graphical virtual world, Boellstorff (60 - 61) expands on Hine's arguments for the study of online cultures in context and formulates a further defense of online only ethnography. Boellstorff (60 - 64) points out that online communities develop their own socio-cultural and economic contexts and that cyber-ethnographers should seek to understand how these contexts develop and influence participants' lives online (Boellstorff, 60-64). Understanding online cultures in context requires researchers to relinquish their a-priori assumptions about problems of authenticity online and attempt to engage with virtual worlds along the same lines as participants (Taylor, "Life in Virtual Worlds," 442). Engaging with graphical virtual worlds on their own terms means interacting with the world and others via an avatar.

\section{Being Entropian}


I have an avatar body... she is female and her name is Twist. Her skin is white and her hair is purple; she is me, but she is not me. We are one and yet, she is other. I can only "be" in this space through her, but she can only act in this world though me - we're symbiotic life form, I guess, a cyborg hybrid of ethnographer and avatar.

Just like in the real world, no two avatars on Calypso look alike. Some people have similar hairstyles, or similar clothes, but everyone is different enough to give the impression of that this world is a collective of individual agents.

There are different races, different genders, tall and short, fat and thin. Most opt to create a conventionally attractive digital self, but there's the occasional obese, balding, slightly disproportional, chappy floating around- a more authentic representation of self perhaps, or a symbolic form of resistance to an image conscious culture, who knows? You just take everyone at face value I guess. I zoom out to a third person view and observe Twist from all sides, she'll do - now, off to shoot some monsters :)

(Entropia - field diary, 15/8/2011)

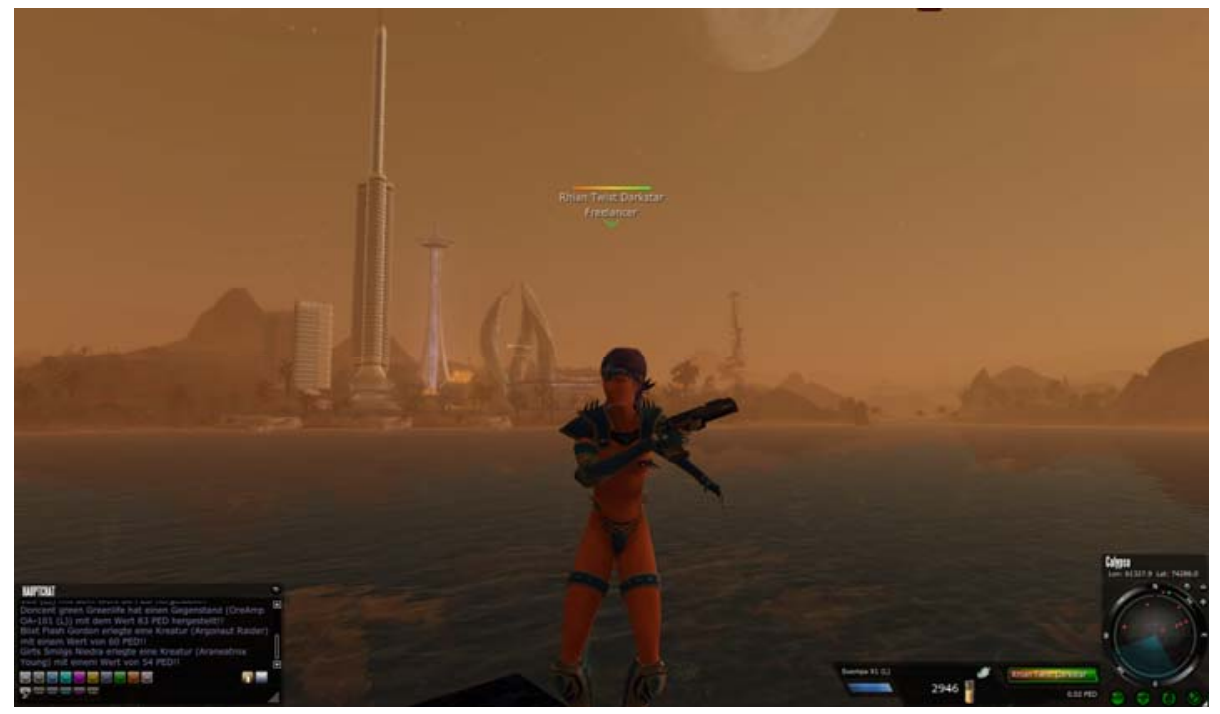

Rhian Twist Darkstar - my avatar (screen shot 15.8.2011)

Digital embodıment brıngs the experıence of "being in the world" or "Dasein" (Heidegger 78) in virtual space closer to the experience of being in physical space than it ever has been before. In Entropia, the world can be viewed through the eyes of your avatar, enabling the user to experience a visual movement through the virtual landscape and an embodied form of agency within the world. This experience of virtual "being" is augmented by the ability to shift between first-and third-person views or to zoom in and out of the world, creating a dimension of hyper-reality through the "generation ... of a real without origin” (Baudrillard, 166).

Graphical worlds, like Entropia, do not attempt to mimic reality, but to create a virtual reality which draws on the physical world just enough to render the space comprehensible and enable immersion. Calypso, for example, has grassy landscapes, buildings, water, gravity, and skies. However, acts which are impossible in the physical world, like looking at the back of your head, teleporting, or fighting giant monsters, become mundane realities in this virtual space. Sensory input is limited to sight and sound, but geographical distance is eradicated as 
players from around the globe interact in real time. The real-time interactions of large numbers of users, and the fact that people return to this virtual world for extended periods of time (often years), has resulted in the development of socio-cultural modes of behavior which are specific to Entropia Universe.

The systems of trade and commerce built into this virtual world's programming have resulted in the development of internally coherent economic and social systems with norms of etiquette, hierarchies, and conventions of interaction. Animals on Calypso are hunted for loot and this loot, like mined and manufactured goods, is worth money on the Entropian market. The monetary value of loot has resulted in the development of hunting etiquette. When hunting, it's considered rude to shoot an animal that someone else has already started shooting; this doesn't mean that it's against the rules or that it doesn't happen, just that it frowned upon, akin to queue jumping in the real world. When this behavioral norm is transgressed, people are often publically reprimanded in the dialogue box. The valediction "gl" (good luck) has also developed, as social norm, in response to the game's cash economy and the fact that hunting, producing, or mining are essentially games of chance. This norm of interaction is simply an acknowledgment that luck is necessary for a successful life on Calypso and that luck on Calypso can result in real-life gains.

Social hierarchies on Calypso reflect players' length of time in the game, their skill levels, their knowledge of social norms and, sometimes, in game capital. These hierarchies are exemplified through the social groups people associate with, the in-game societies to which people belong and the places they frequent; Swamp Camp, for example, is a well-known "newbie" hangout because of the relatively tame creatures in this area. These social hierarchies serve to differentiate new players ("n00bs") from established members of the community and determine the level of respect, or assistance, that people can expect from others. This virtual world has become an alternate domain of human existence where the ethnographer can observe how social norms develop in response to the economic contexts within which they are embedded. The avatar is the vehicle through which an embodied experience of this hyper-reality becomes possible, where identity is fragmented and reconstituted through the simultaneous experience of being both self and other in a space where the simulation is the reality.

Avatars are integral to participants’ performance and experience of self within virtual communities. They are not only vehicles for interacting with the world, but also the means by which people engage with the community and others within it (Taylor, "Life in Virtual Worlds," 474). Avatar bodies facilitate users' experiences of social life online, creating a sense and external appearance of presence in the world. When creating an avatar, the user must make explicit choices about the gender, race, appearance, and sometimes species of their digital self. This customisation positions the avatar as a medium for the expression of identity and the user's virtual and real-life affiliations; the avatar, as Taylor explains, thus becomes "a central object around which some performance of identity [is] structured" (Taylor, "Living Digitally," 53). As an outward signifier of identity the avatar body is subject to interpretation by others, just like the physical body, an interpretation over which the user has little control (Taylor, "Living Digitally," 56). The reading of your avatar body by others creates the sense that avatar possesses a degree of autonomy and a socially embodied existence. Avatars' bodies, like real bodies, can be read sexually by others and, within some virtual worlds, they can even perform virtual sexual acts. Avatars are "born" when the user creates them, but in Entropia they can continue to exist even after the users' death and be bequeathed to relatives or friends. As such, the avatar brings the plurality of self to the fore. This experience of the plurality of self is exemplified in the way people talk about their 
avatars; users "fluctuate in their use of third - and first-person language to describe their experience" (Taylor, "Living Digitally," 57), also sometimes addressing the avatar-user combination as "we".

For the cyber-ethnographer, the avatar exemplifies the duality inherent in the ethnographic method, where the ethnographer is required to be both participant and observer at once. The avatar simultaneously divides and combines these dual roles. The digital participant is separated from the physical observer; the avatar participates in the world, whilst the ethnographer watches from the other side of the screen. However, the two are also united in the "we" of the avatar-ethnographer combination because they depend on each other for their existence. The avatar needs the ethnographer in order act and the ethnographer needs the avatar in order to study the virtual world. The avatar is also a vehicle for the creation and experiencing of place.

\section{Cyberspace as place}

I had decided to explore Calypso in more detail. We (Twist and I) flitted from teleporter to teleporter, wandering away from of the safety of outposts and cities, just as far as we dared. I was mindful of the warnings of an early colonist from a YouTube clip I'd watched recently; "There are creatures here that make Earth's extinct dinosaurs look tame!" I had experience of these creatures from hunts and knew, only too well, how quickly Twist could suffer a costly and inconvenient death that would send us rushing back to the nearest revival outpost.

I was engrossed in the otherworldly beauty of Calypso's landscapes, when I teleported into Twin Peaks. The peaceful solitude I'd experienced in the wilderness of Calypso came to an abrupt halt, as I stepped out of the teleporter and suddenly had to negotiate my way around innumerable avatars. The dialogue box, once again, exploded with chatter, but this time it was offers of trade, sales, and services;

"Selling refined lyst (317) alic (20) Melch (139)",

"Buying ores/enmatters/wools/hides @balcony",

$"++++$ www.atlashavenradio.com $++++"$,

"*****selling sweat 2.3PED/K@TP",

"Taxi- Quad Interceptor - Calypso > FOMA 10PED".

It was like being in the middle of a busy bazaar, with everyone shouting their wares. Avatars stood around the teleporter (TP), some moving, some still. Others ran from person to person, probably arranging transactions.

(Entropia - field diary, 8/9/2011)

The avatar, as a means of social interaction, is integral to the creation of place in cyberspace. Within graphical virtual worlds, people "don't simply chat in disembodied spaces, but use their avatars to gather for social events ... and simply hanging out" (Taylor, "Living Digitally," 47). The fact that people use their avatars to gather in certain areas contributes to 
the creation of a sense of place. A sense of place is constructed via the social interactions that occur in a given area and the narratives of place that these social experiences create (Wood, Kaiser and Abrams, 1-2). The gathering of avatars in certain locations, and the interactions between avatars that occur at these virtual gathering points, contributes to the creation of narratives of place within virtual worlds. Within Entropia, the city "Twin Peaks" has emerged as a virtual third place: an informal public gathering place and significant site of social interaction (Moore, Gathman and Ducheneaut, 231).

Twin Peaks is one of many cities on Calypso, but it, in particular, has become a hub of trade within this virtual world. Just one encounter with this virtual city enables the user to identify Twin Peaks as a centre of commerce. As soon as the player steps out of the teleport station in the centre of city, the dialogue box in the corner of the screen erupts with offers of sales and trade. The experiential sense of entering a hub of interaction is reinforced by the visual impression of lots of other avatars standing around the teleporter. The new player can immediately recognise that this is a spot where others can be found and this knowledge leads people back here when they want to seek advice, trade, form hunting parties, or simply hang out. The consensus which emerges around the social meaning of this place results in the continual reproduction of its character. The character of Twin Peaks as a centre of trade and interaction is also reinforced when participants direct new players there in response to questions about where to buy or sell virtual goods. Functional narratives of place, such as the narrative of Twin Peaks, are created through this user consensus about the social meaning of this city for the Entropian community. This micro-level narrative of place is complemented by the broader sci-fi game narrative which contextualises users' experiences on Calypso.

Entropia's narrative of interstellar conquest and colonization is reflected in the design of the virtual landscape: the buildings look futuristic, the planet is peppered with outlandish flora and fauna, there are spaceships, and the inhabitants of Calypso are under constant threat by malevolent otherworldly life forms. The game play also reflects this narrative: players are referred to as colonists and events such as robot attacks are common. The game narrative provides players with a form of virtual cosmology; it's a means of ordering and explaining the virtual universe and the roles of self and other within it. However, the narrative creation of a place in Entropia also extends beyond the digital borders of Calypso.

Narratives of place in Entropia are solidified through user discourses on forums, wikis, and online video hosting sites. Players reinforce the game narrative by creating wikis documenting animal life on Calypso or YouTube videos about colonization, life on calypso and hunts, and through forum discussions about the latest findings of "The Imperial Exobiology Institute". The retelling of the game narrative via these "out of world" discourses confirms the validity of peoples' experiences of place on Calypso by highlighting the shared nature of these experiences. The shared understandings of place, exemplified through these recognisable narratives, strengthen players' sense of community and validates the experiential reality of their life experiences on Calypso. The cyber-ethnographer also becomes part of the collective creation of narratives of place in cyberspace through the documentation of their experiences within virtual worlds.

Cyber-ethnographic studies simultaneously shape and reflect the social realities which they document. The role of ethnographers in constructing social realities, through ethnographic reporting, has been widely recognised since at least the mid-1980s (see Clifford and Marcus, 10-11). The origins of cyber-ethnography within the discipline of cultural anthropology are exemplified through the sub-discipline's recognition of the manner in which cyber-realities are constructed, not through physical or material processes but through performance, 
narrative, and the social attribution of meaning. The social construction of reality becomes particularly apparent when material referents are removed. The role of the ethnographer as a participant in the creation of social reality comes to the fore in virtual worlds because the mystifying power of physical and materials realities is eliminated. The social and experiential realities of virtual worlds are created through the narratives that game designers and players create about, and within, these worlds. By documenting life in virtual worlds, the ethnographer becomes one of many participants in the creation of dynamic narrative of place.

\section{Conclusions: this is just the beginning...}

Virtual worlds change and evolve as quickly as the technologies through which they are created. The discipline of cyber-ethnography has had to evolve alongside these technologies and in doing so it has contributed to both our understandings of digital sociality and the ongoing development of the ethnographic method. The possibility of studying communities that exist only online has led to a re-examination of the primacy attributed to the face-to-face encounter within ethnographic research and a reiteration of the ethnographic axiom of studying cultures in context. The application of the ethnographic method to virtual worlds, like Entropia Universe, draws attention to the reality of the social worlds that exist in digital space and raises awareness of how social consensus can result in the development of a sense of place and presence, even within a fictitious hyper-reality. Cyber-ethnography also draws attention to the manner in which ethnographic reporting contributes to the construction of social realities by enabling ethnographers to see past the supposed "factual reality" of the material world. Virtual world communities have developed rapidly over the past twenty years and will undoubtedly continue to develop as internet technologies progress. The changing nature of life online means that cyber-ethnographic studies become snapshots of a fleeting digital present, shaping our image of that present and documenting the evolution of human life online as it occurs.

Cyber-ethnography has the potential to revolutionise our understandings of both reality and fiction through the documentation of real-life interactions in ethereal virtual worlds. The continued examination of the shrinking dialectic between the real and the virtual will undoubtedly continue as the online population grows. Social interactions via cyberspace are increasingly becoming a day-to-day occurrence for many people throughout the world, but exactly how these interactions will shape the future of human sociality remains to be seen. Life on the internet is collective, social, cultural, and analysable using the ethnographic method. A new frontier of ethnographic enquiry is emerging and a new generation of ethnographers is ready and waiting to explore this frontier.

\section{WORKS CITED}

Bartle, Richard A. (2004). Designing Virtual Worlds. United States: New Riders Publishing.

Baudrillard, Jean. (1994). Simulacra and Simulation. Trans. Glaser, S. F. Ann Arbor: University of Michigan Press.

Bell, Mark W. (2008). Toward a Definition of 'Virtual Worlds.' Journal of Virtual Worlds Research, 1.1.

Boellstorff, Tom. (2008). Coming of Age in Second Life: An Anthropologist Explores the Virtually Human. Princeton, N.J. : Princeton University Press. 
Cherny, Lynn. (1995). The Modal Complexity of Speech Events in a Social Mud. Electronic Journal of Communication, 5.4.

Clifford, James; Marcus, George, E. (1986). Writing Culture: The Poetics and Politics of Ethnography. Berkley, Los Angeles: University of California Press.

Dibbell, Julien. (1998). My Tiny Life: Crime and Passion in a Virtual World. New York: Henry Holt and Company, Inc.

Driscoll, Catherine, and Gregg, Melissa. (2010). My Profile: The Ethics of Virtual Ethnography. Emotion, Society and Space, 3.1: 15-20.

Evans, Leighton. (2010). Authenticity Online: Using Webnography to Address Phenomenological Concerns. 5th Global Conference: Cybercultures, exploring critical issues.

Hafner, Katie, and Lyon, Matthew. (1998). Where Wizards Stay up Late: The Origins of the Internet. New York: Touchstone.

Hakken, David. (1999). Cyborgs@Cyberspace? : An Ethnographer Looks to the Future. New York: Routledge.

Heidegger, Martin. (1973). Being and Time. Trans. Macquarie, J. and E. Robinson. Oxford: Blackwell.

Hine, Christine. (2000). Virtual Ethnography. Thousand Oaks, California: Sage.

Kelly, Jeremy. N. (2004). Play Time: The Problem of Abundance in MMMORPG. www.anthemion.com.

Masterson, James. (1994). Ethnography of a Virtual Society: Or, How a Gangling, Wiry Half-Elf Found a Way to Fit In. Montana: University of Montana.

Miller, Daniel., and Slater, Don. (2000). The Internet: An Ethnographic Approach. Oxford: Berg.

Moore, Robert. J., Gathman, E., Cabell, Hankinson and Ducheneaut, Nicholas. (2009). From 3d Space to Third Place: The Social Life of Small Virtual Spaces. Human Organization, 68.2: 230-40.

Rosenberg, Michael. S. (1992). Virtual Reality: Reflections of Life, Dreams, and Technology, an Ethnography of a Computer Society. $<\mathrm{ftp}$ //sunsite.unc.edu/pub/academic/communications/papers/muds/muds/Ethnograph y-of-a-Computer-Society>.

Rybas, Natalia., and Radhika. Gajjala. (2007). Developing Cyberethnographic Research Methods for Understanding Digitally Mediated Identities. Forum: Qualitative social research, sozialforschung, 8.3. <http://www.qualitativeresearch.net/index.php/fqs/article/view/282>. 
Taylor, T.L. (1999). Life in Virtual Worlds: Plural Existence, Multimodalities, and Other Online Research Challenges. American Behavioural Scientist, 43.3: 436-49. Print.

---. (2002). Living Digitally: Embodiment in Virtual Worlds. The Social Life of Avatars: Presence and Interaction in Shared Virtual Environments. Ed. Schroeder, R. London: Springer-Verlag. Print.

Teli, Maurizio; Pisanu, Francesco and Hakken, David. (2007). The Internet as a Library-ofPeople: For a Cyberethnography of Online Groups. Forum: Qualitative social research, sozialforschung, 8.3. <http://www.qualitativeresearch.net/index.php/fqs/article/view/283/622>.

Tuan, Yi-Fu. (1991). Language and the Making of Place: A Narrative Descriptive Approach. Annals of the Association of American Geographers, 81.4: 684-96.

Turkle, Sherry. (1995). Life on the Screen: Identity in the Age of the Internet. New York: Simon \& Schuster.

Wellman, Barry. (2004). The Three Ages of Internet Studies: Ten, Five and Zero Years Ago. New Media and Society, 6.1: 123-29.

Wood, Denis; Kaiser, Ward and Abrams, Bob. (2006). Seeing through Maps: Many Ways to See the World. Oxford: New Internationalist. 